\title{
COMPLEXOS POLIMÉRICOS OBTIDOS A PARTIR DE CONCENTRADO PROTEÍCO DE SORO E POLISSACARÍDEOS
}

\author{
V. C. ZUVANOV ${ }^{1}$ e E. E. G. ROJAS ${ }^{1,2}$ \\ ${ }^{1}$ Universidade Federal Rural de Rio de Janeiro, Programa de Pós-graduação em Ciência e \\ Tecnologia de Alimentos \\ ${ }^{2}$ Universidade Federal Fluminense, Departamento de Engenharia de Agronegócios \\ E-mail para contato: edwin@vm.uff.br
}

RESUMO - A otimização do processo de formação de complexos poliméricos entre concentrado proteico do soro (WPC) e os polissacarídeos carragena, goma arábica, goma xantana foi realizada através da metodologia de superfície de resposta, com o objetivo de definir as condições ótimas para a formação de cada complexo. O delineamento composto central rotacional (DCCR) para três variáveis independentes foi utilizado como planejamento do experimento. A influência das variáveis estudadas (concentração salina, massa de polissacarídeo e $\mathrm{pH}$ ) na formação do complexo foi avaliada e conclui-se que cada sistema WPC-polissacarídeo obteve um comportamento específico, de acordo com a estrutura e carga do polissacarídeo envolvido que consequente influenciou na interação proteína-polissacarídeo. O modelo matemático que melhor se ajustou aos dados experimentais foi o do complexo WPC-goma arábica que apresentou alto coeficiente de determinação $\left(\mathrm{R}^{2}=0,88\right)$.

\section{INTRODUÇÃO}

A proteína e o polissacarídeo estão unidos na fase rica em biopolímeros pela força eletrostática e podem tomar a forma de um coacervado ou um precipitado (TOLSTOGUZOV, 2007). Os complexos coacervados combinam as propriedades físico-químicas e funcionais das macromoléculas que os constituem, especialmente seu caráter hidrofóbico/hidrofílico. Devido às suas estruturas específicas, tamanho e composição, os complexos proteína-polissacarídeo e os coacervados estão exibindo uma ampla gama de propriedades funcionalidades úteis para o desenvolvimento de produtos alimentares complexos (SCHMITT e TURGEON, 2010).

O concentrado protéico de soro de leite (Whey Protein Concentrate-WPC) é o produto obtido pela remoção dos constituintes não-protéicos do soro, de tal modo que o produto final seco tenha 25-89\% de concentração de proteína. É obtido por métodos de separação que não utilizam tratamento térmico (por exemplo, ultrafiltração), por isso se diferencia de outros produtos quanto às suas propriedades funcionais, uma vez que apresenta conformação estrutural preservada (ANTUNES, 2003).

As carragenas são um grupo de polissacarídeos naturais que estão presentes na estrutura celular de algas do tipo Rodophyceae. Este tipo de polissacarídeo presente em algas possui características que o diferencia dos polissacarídeos isolados de outros vegetais, como por exemplo, 
presença de unidades de 3,6-anidrogalactose e de grupos sulfato. (SPAGNUOLO et al., 2005). A carragena é um ingrediente alimentar bem estabelecido, com um amplo número de aplicações devido às suas propriedades físico-químicas. Confere estabilidade, corpo e diminuição da atividade de água quando adicionadas a produtos lácteos, cárneos, sorvetes, entre outros. (BALDASSO, 2004; BELLAVITA e GUANANJA, 1999; SPAGNUOLO et al., 2005).

A goma arábica é o exsudato gomoso dessecado dos troncos e dos ramos de Acacia senegal ou de outras espécies africanas de acácia. Caracteriza a goma vegetal mais utilizada pois além de espessante, é também um ótimo estabilizante de emulsões (BARUFFALDI, 1998). Os três grandes campos de aplicação da goma arábica na indústria de alimentos são: confeitos, emulsão de aromas em bebidas e encapsulamento de aromas. A goma arábica é também um ingrediente bi-funcional, além de suas propriedades funcionais como espessante e estabilizante, possui efeito prébiótico no organismo humano (HEBBEL, 1979).

A goma xantana é um polissacarídeo sintetizado pela bactéria fitopatogênica Xanthomonas campestris. Apresenta-se com uma estrutura primária composta de repetidas unidades pentassacarídicas (JANSSON et al., 1975). Funciona muito bem como estabilizante em produtos à base de água, possui boa solubilidade. Possui comportamento pseudoplástico quando em solução, torna-se rala quando sobre ela é aplicada força de cisalhamento (BALDASSO, 2004; PAGNO, 2009). As operações de bombeamento na fase de produção do alimento são facilitadas pelo seu comportamento pseudoplástico, fazendo com que produtos como, cremes para saladas fluam com facilidade de um frasco ou garrafa. Por isso, é utilizada na fabricação de molhos para saladas, bebidas, geléias, produtos cárneos, enlatados, e sopas (BALDASSO, 2004).

Assim, o objetivo deste trabalho foi otimizar o processo de obtenção de complexos poliméricos obtidos a partir do WPC e dos polissacarídeos carragena, goma arábica e goma xantana.

\section{MATERIAIS E MÉTODOS}

\subsection{Material}

Os polissacarídeos carragena, goma arábica e goma xantana foram adquiridos de Sigma Aldrich (St. Louis, USA). O concentrado protéico de soro de leite (WPC), com teor de proteína de $53 \%$, foi adquirido de CPKelco (Atlanta, USA). Nos experimentos foram empregados reagentes químicos de grau analítico e água deionizada.

\subsection{Metodologia}

\subsubsection{Planejamento experimental}

Foi empregado o delineamento composto central rotacional (DCCR) para três variáveis independentes, com cinco níveis cada uma (RODRIGUES e IEMMA, 2005), como mostra a Tabela 1. A variável dependente (Y) foi a turbidez, calculada a partir da leitura de transmitância do sobrenadante. Foi realizado um fatorial completo $2^{3}$, seis repetições do ponto central e seis pontos axiais, totalizando 20 experimentos (Tabela 2). Na otimização do processo de formação dos 
coacervados foi utilizada a metodologia de superfície de resposta (MSR) que avalia simultaneamente a influência das três variáveis $\mathrm{pH}$, concentração salina e massa de polissacarídeo.

Tabela 1. Variáveis e níveis do planejamento experimental para formação de coacervados.

\begin{tabular}{|c|c|c|c|c|c|c|}
\hline \multirow{2}{*}{ Variáveis } & \multirow{2}{*}{ Símbolo } & \multicolumn{5}{|c|}{ Níveis } \\
\hline & & $-1,68$ & -1 & 0 & 1 & 1,68 \\
\hline $\mathrm{pH}$ & $\mathrm{X}_{1}$ & 3,0 & 4,2 & 6,0 & 7,8 & 9,0 \\
\hline $\begin{array}{l}\text { Concentração de } \mathrm{NaCl} \\
(\mathrm{mol} / \mathrm{L})\end{array}$ & $\mathrm{X}_{2}$ & 0 & 0,20 & 0,50 & 0,80 & 1,0 \\
\hline Polissacarídeo (mg) & $\mathrm{X}_{3}$ & 2,5 & 7,0 & 13,8 & 20,4 & 25,0 \\
\hline
\end{tabular}

\subsubsection{Formação dos complexos coacervados}

As misturas contendo WPC - polissacarídeo foram preparadas seguindo a metodologia proposta na literatura (BASTOS et al., 2010; ABERKANE et al., 2010; WEINBRECK et al., 2004). Inicialmente, foram preparadas soluções contendo $1 \%(\mathrm{~m} / \mathrm{v})$ de cada polissacarídeo e soluçõestampão com pH e concentração salina pré-determinados. Para o preparo da mistura, pesou-se 100 mg de WPC e em seguida adicionou-se a solução-tampão específica e o volume de polissacarídeo (pré-determinado). As amostras foram agitadas durante 2 horas a $25^{\circ} \mathrm{C}$ no agitador orbital (TECNAL, TE 420, Brasil). A fim de garantir a formação dos complexos poliméricos, as amostras foram mantidas sob refrigeração por $24 \mathrm{~h}$ (CAMILO, 2007) e depois centrifugadas (CIENTEC, mod. TC-6000, Brasil) a 6.000 rpm durante 30 min.

\subsubsection{Caracterização dos complexos coacervados}

\section{Turbidimetria}

Após a centrifugação, foi retirada uma alíquota de $4 \mathrm{~mL}$ do sobrenadante para determinação da transmitância no espectrofotômetro (Biochrom mod. LIBRA S12, Inglaterra) com comprimento de onda de $400 \mathrm{~nm}$. Segundo ABERKANE et al. (2010) e CHOLLAKUP et al. (2010).

\section{Caracterização morfológica}

Foram preparadas amostras apontadas pela análise estatística como ótimas em relação à turbidez (ponto ótimo de minimização). Seus complexos precipitados foram secos à vácuo (SPEED VAC SC 110, SAVANT INC., USA) e posteriormente analisados quanto à sua microestrutura por microscopia eletrônica de varredura - MEV (ZEISS, EVO MA10, Alemanha). O microscópio foi operado no modo de elétrons secundários com tensão de aceleração de 20 kV.

\subsubsection{Análise estatística}

Os dados experimentais foram ajustados por regressão não linear à equação polinomial de $2^{\circ}$. grau. Para tanto, foi usado o pacote estatístico SAS ${ }^{\circledR}$ v. 9.0 (SAS Institute Inc., NC, USA). O modelo obtido foi validado estatisticamente através da análise de variância. 


\section{RESULTADOS E DISCUSSÃO}

\subsection{Formação de complexos poliméricos WPC-polissacarídeos}

Na Tabela 2 são apresentados os resultados da variável dependente Turbidez (Y) para os complexos formados por WPC e polissacarídeos.

Tabela 2 - Variável dependente (Y) de cada complexo formado entre WPC e polissacarídeos

\begin{tabular}{ccccccc}
\hline Ensaio & $\mathrm{pH}$ & $\begin{array}{c}\mathrm{NaCl} \\
\left(\mathrm{X}_{2}\right)\end{array}$ & $\begin{array}{c}\text { Polissac. } \\
\left(\mathrm{X}_{3}\right)\end{array}$ & $\begin{array}{c}\mathrm{Y}_{1} \\
(\mathbf{C A})\end{array}$ & $\begin{array}{c}\mathrm{Y}_{2} \\
(\mathbf{G A})\end{array}$ & $\begin{array}{c}\mathrm{Y}_{3} \\
(\mathbf{G X})\end{array}$ \\
\hline 1 & -1 & -1 & -1 & 0,036 & 0,120 & 0,242 \\
2 & -1 & -1 & +1 & 0,036 & 0,155 & 1,115 \\
3 & -1 & +1 & -1 & 0,158 & 0,159 & 0,443 \\
4 & -1 & +1 & +1 & 0,114 & 0,203 & 2,244 \\
5 & +1 & -1 & -1 & 0,272 & 0,544 & 0,591 \\
6 & +1 & -1 & +1 & 0,232 & 0,389 & 1,309 \\
7 & +1 & +1 & -1 & 0,305 & 0,440 & 0,465 \\
8 & +1 & +1 & +1 & 0,203 & 0,345 & 0,858 \\
9 & $-1,682$ & 0 & 0 & 0,035 & 0,070 & 0,511 \\
10 & $+1,682$ & 0 & 0 & 0,566 & 0,652 & 1,027 \\
11 & 0 & $-1,682$ & 0 & 0,221 & 0,204 & 0,406 \\
12 & 0 & $+1,682$ & 0 & 0,228 & 0,355 & 3,107 \\
13 & 0 & 0 & $-1,682$ & 0,264 & 0,332 & 0,796 \\
14 & 0 & 0 & $+1,682$ & 0,165 & 0,390 & 4,017 \\
15 & 0 & 0 & 0 & 0,177 & 0,311 & 2,996 \\
16 & 0 & 0 & 0 & 0,166 & 0,304 & 2,976 \\
17 & 0 & 0 & 0 & 0,171 & 0,326 & 2,830 \\
18 & 0 & 0 & 0 & 0,163 & 0,278 & 2,976 \\
19 & 0 & 0 & 0 & 0,209 & 0,315 & 2,976 \\
20 & 0 & 0 & 0 & 0,212 & 0,319 & 2,781 \\
\hline
\end{tabular}

(CA) carragena; (GA) goma arábica; (GX) goma xantana;

Para o complexo WPC-carragena, o valor de turbidez aumentou com o incremento do $\mathrm{pH}$. Isso significa que quanto menor o valor de $\mathrm{pH}$ na faixa estudada, mais complexo polimérico foi formado entre WPC e carragena. Neste trabalho, a condição ótima para formação do complexo foi em pH 4,4; valor localizado entre o pKa da carragena $(2,0)$ e o pI da $\beta$-lactoglobulina $(5,3)$, proteína presente em maior concentração no soro de queijo. A interação entre proteína e carragena é naturalmente eletrostática e devido à influência do $\mathrm{pH}$ na ionização das cargas das proteínas, complexos eletrostáticos devem se formar na estreita faixa de $\mathrm{pH}$ onde os biopolímeros possuem cargas opostas (WEINBRECK et al., 2004). Em relação ao complexo WPC-goma arábica, onde mais complexo polimérico foi formado com a diminuição do $\mathrm{pH}$. A condição ótima para a formação do complexo foi $\mathrm{pH} 4,3$, valor bem próximo ao do complexo discutido anteriormente. Conforme discussão acima, o resultado encontrado também foi como o esperado.

No caso do complexo WPC-goma xantana, a turbidez do sistema aumenta com o incremento 
da concentração salina, ou seja, mais complexo polimérico é formado em valores mais baixos de concentração salina. De acordo com Bertrand e Turgeon (2007) que estudaram o melhoramento das propriedades gelificantes do isolado protéico de soro com a adição de goma xantana, a incorporação de sal em uma solução mista de proteína-polissacarídeo favorece a separação de fase segregativa porque o sal gera uma proteção das cargas presentes nos biopolímeros, e consequentemente reduz as interações eletrostáticas entre eles. Po outro lado uma diminuição na massa de goma xantana, dentro da faixa estudada, produz uma menor turbidez do sistema. Segundo Lii et al. (2003) que estudaram os complexos formados entre goma xantana e ovoalbumina, provavelmente a faixa de valores baixos de massa de goma xantana onde mais complexo foi formado tratava-se de uma região próxima à relação estequiométrica massa de goma xantana : proteína, e acima dessa região, o componente goma xantana estava em excesso e o valor de turbidez do sistema foi maior.

\subsection{Otimização da formação de complexo polimérico}

As estimativas de cada parâmetro do modelo de primeira ordem ou segunda ordem considerado significativo, além do valor t do teste de Student e do valor da probabilidade (Pr) de cada parâmetro podem ser encontrados na Tabela 2. Nesta Tabela pode-se observar as equações de primeira ou segunda ordem, considerando as variáveis significativas $(\operatorname{Pr}<0,05)$ de cada complexo, como resultado da minimização da variável resposta turbidez.

Tabela 2- Equações geradas pela minimização da variável resposta de cada complexo.

\begin{tabular}{lc}
\hline Equação & $\mathbf{R}^{\mathbf{2}}$ \\
\hline (1) $\mathrm{Y} 1=-0,18447+0,06352 * \mathrm{X}_{1}$ & 0,75 \\
(2) $\mathrm{Y} 1=-0,46167+0,130541 * \mathrm{X}_{1}+0,019656 * \mathrm{X}_{3}-0,00341 * \mathrm{X}_{1} * \mathrm{X}_{3}$ & 0,88 \\
(3) $\mathrm{Y} 1=-9,08875+3,224549 * \mathrm{X}_{1}+7,07297 * \mathrm{X}_{2}-0,268557 * \mathrm{X}_{1}{ }^{2}-5,780493 * \mathrm{X}_{2}{ }^{2}$ & 0,81 \\
\hline (1) Complexo WPC-carragena; (2) Complexo WPC -goma arábica; (3) Complexo WPC -goma xantana
\end{tabular}

\subsection{Caracterização morfológica}

Utilizando as condições ótimas de preparo para os complexos poliméricos (Tabela 12), as imagens de MEV destas estruturas são apresentadas na Figura 1. A Figura 1A demonstra a estrutura do WPC caracterizado por estruturas globulares, correspondendo às formas globulares das proteínas $\beta$-lactoglobulina e $\alpha$-lactoalbumina, proteínas presentes em maior concentração no soro de queijo. As Figuras 1B- 1D demonstram a estruturas dos polissacarídeos isolados. É possível também visualizar a formação do complexo polimérico entre WPC e os polissacarídeos carragena, goma arábica e goma xantana (Figuras 1E-1G). Estes complexos possuem características morfológicas específicas para cada um deles e demonstram ser estruturas diferentes das iniciais. 

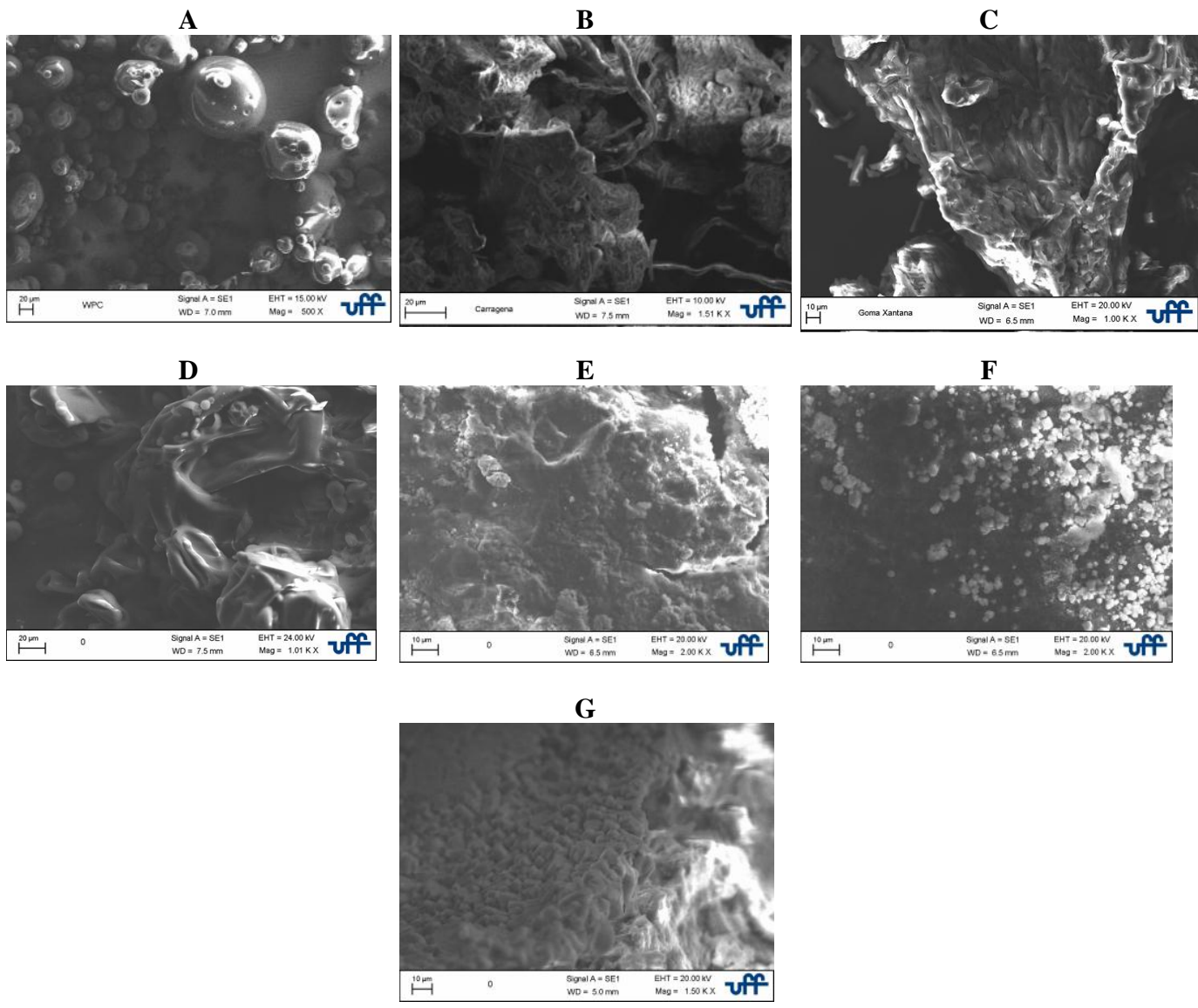

Figura 1 - Fotomicrografias de WPC, polissacarídeos e complexos poliméricos preparados sob condições ótimas e secos em estufa à vácuo. (A) WPC, (B) Carragena, (C) Goma arábica, (D) Goma xantana, (E) Complexo polimérico WPC-carragena, (F) Complexo polimérico WPC-goma arábica, (G) Complexo polimérico WPC-goma xantana.

\section{CONCLUSÕES}

Foi possível otimizar o processo de obtenção de complexos poliméricos formados a partir do WPC e os polissacarídeos carragena, goma arábica e goma xantana através da metodologia de superfície de resposta. A influência das variáveis estudadas na formação do complexo foi estudada e conclui-se que cada sistema WPC-polissacarídeo obteve um comportamento específico, de acordo com a estrutura do polissacarídeo envolvido e consequente interação proteína-polissacarídeo.

\section{REFERÊNCIAS}

ABERKANE, L.; JASNIEWSKI, J.; GAIANI, C.; SCHER, J.; SANCHEZ, C. Thermodynamic Characterization of Acacia Gum- $\beta$-Lactoglobulin Complex Coacervation. Langmuir, v. 26, n. 15, p. 12523-12533, 2010. 
ANTUNES, A. J. Funcionalidade de proteínas do soro de leite bovino, 1ª ed., Editora Manole Ltda., 2003. Editora Manole Ltda., 2003.

BALDASSO, C.; MARTINS, S.; SANGIOVANNI, P. Espessantes. Universidade Federal do Rio Grande do Sul, Porto Alegre, 2004.

BARUFFALDI, R.; OLIVEIRA, M. N. Fundamentos de Tecnologia de Alimentos. Vol.3. Ed. Atheneu. São Paulo, 1998.

BASTOS, D. S.; BARRETO, B. N.; SOUZA, H. K. S.; BASTOS, M.; ROCHA-LEÃO, M. H. M.; ANDRADE, C. T.; GONÇALVES, M. P. Characterization Of A Chitosan Sample Extracted From Brazilian Shrimps And Its Application To Obtain Insoluble Complexes With A Commercial Whey Protein Isolate. Food Hydrocolloids, v. 24, p. 709-718, 2010.

BELLAVITA, R.; GUANANJA, G. Carragenina con nuevas propriedades: La alternativa vegetal de la gelatina. Revista Ênfasis Alimentacion, Argentina, Ano 5, n. 4, p. 42-43, abr. 1999.

BERTRAND, M. E.; TURGEON, S. L. Improved gelling properties of whey protein isolate by addition of xanthan gun. Food Hydrocolloids, n. 21, v. 2, p. 159-166, 2007.

CHOLLAKUP, R.; SMITTHIPONG, W.; EISENBACH, C. D.; TIRREL, M. Phase behavior and coacervation of aqueous poly(acrylic acid)-poly(allymine) solutions. Macromolecules. v. 43, p. 2518-2528, 2010.

HEBBEL, H. S. Aditivos y Contaminantes de Alimentos. Ed. Fundacion Chile. Santiago-Chile. 1979.

JANSSON, P. E.; KENNE, L.; LINDBERG, B. Structure of the extracellular polysaccharide from Xanthomonas campestris. Carbohydrate Research, v. 45, p. 275-282, 1975.

LII, C. Y.; LIAW, S. C.; TOMASIK, P. Xanthan gum-ovalbumin complexes from electrosynthesis and coacervation. Pol. J. Food Nutr. Sci., v. 12/53, n. 3, p. 25-29, 2003.

RODRIGUES, M. I.; IEMMA, A. F. Planejamento de experimentos e otimização de processos: uma estratégia sequiêncial de planejamentos. Campinas: Editora Casa do Pão, 2005. 325 p.

SCHMITT, C.; TURGEON, S. L. Protein/polysaccharide complexes and coacervates in food systems. Adv. Colloid Interface Sci, v. 167, p. 63-70, 2010.

SPAGNUOLO, P. A.; DALGLEISH, D. G.; GOFF, H. D.; MORRIS, E. R. Kappa-carrageenan interactions in systems containing casein micelles and polysaccharide stabilizers. Food Hydrocolloids, v. 19, p. 371-377, 2005.

TOLSTOGUZOV, V. B. Ingredient interactions: in complex foods: Aggregation and phase separation. In: Understanding and controlling the microstructure of complex foods. D. J. McClements ed, Chapter 7. CRC Press, RocaRaton, Woodhead Publishing Limited. Cambridge, UK. p. 185-206, 2007. 
WEINBRECK, F.; NIEUWENHUIJSE, H.; ROBINJN, G. W.; KRUIF, C. G. Complexation of whey proteins with carrageenan. Journal of Agricultural and Food Chemistry, ACS Publication, n. 52, p. 3550-3555, 2004. 